Mirai. Estudios Japoneses

ISSN-e: 2531-145X

http://dx.doi.org/10.5209/MIRA.60497

\title{
El devenir turístico de Kumano, su adaptación a las nuevas tendencias de la espiritualidad japonesa y su proyección internacional a través del hermanamiento con el Camino de Santiago
}

\author{
$\mathrm{M}^{\mathrm{a}}$ Dolores Rodríguez del Alisal ${ }^{1}$
}

Fechas

Resumen. Japón tiene una tradición muy antigua en la actividad de la peregrinación y ésta se halla muy relacionada con el turismo y las visitas para disfrutar del paisaje, la naturaleza y los lugares míticos del país. Los viajes dirigidos a lugares de culto han movido multitudes desde la era premoderna y, con otra forma, continúan siendo un factor de atracción para la población japonesa. En este artículo, voy a centrarme en el viejo camino a Kumano (Kumano Kodō), situado en la cordillera de Kii, un lugar especialmente significativo en la formación de los mitos de fundación de la nación japonesa y determinante para el sentimiento de identidad de sus habitantes. Señalaré su evolución en nuestros días, muy marcada por su pasado y, también, por las diferentes campañas turísticas, por las nuevas tendencias en la espiritualidad de la población y, más recientemente, por su proyección internacional debido al acuerdo de hermanamiento de sus caminos de peregrinación con el Camino de Santiago.

Palabras clave: peregrinación; publicidad; identidad; power spots; hermanamiento.

\begin{abstract}
Japan has a long tradition related to pilgrimages and the Kumano pilgrimage is closely related to Japan's origins and, also, to the development of tourism. Since the pre-modern period, pilgrimages and spiritual tourism have moved crowds and nowadays, in a different form, they still exert attraction over the Japanese population. The focus of my contribution is the pilgrimage of Kumano Kodō, situated in the Kii Mountain Range, a special significant place in the formation of the National Myths of Japan and the identity consciousness of the Japanese people. I will point out how this pilgrimage route has evolved throughout time up to the present day when it has been influenced not only by different tourist campaigns but also by the new trends in Japanese spirituality and by the International Agreement for the Twinning of Pilgrimage Paths with Santiago de Compostela.
\end{abstract}

Key Words: Tourism; Furusato Japan; power-spots; international twinning pilgrimage.

Sumario: 1. Peregrinaciones, viaje y turismo en Japón; 2. Proceso y cambio en el viaje turístico de Japón; 3. Descubriendo Japón con nostalgia; 4. El exotismo de la propia tradición; 5. Kumano, cuna del turismo espiritual en la tradición japonesa; 6 . Kumano, entre la tradición y el cambio; 7. Bosques sagrados, aguas milagrosas y alimentos naturales: el renacer en las forestas de Kumano; 8. Ponerse a tono, física, mental y espiritualmente en Kumano; 9. El fenómeno power-spot y Kumano; 10. Vinculación internacional entre las sendas hacia Kumano y los caminos a Santiago; 11. Conclusiones.

Profesora de Japonés. Escuela Oficial de Idiomas de Madrid. ma.r.delalisal@gmail.com 
Cómo citar: Rodríguez del Alisal, $M^{a} D$. (2018). El devenir turístico de Kumano, su adaptación a las nuevas tendencias de la espiritualidad japonesa y su proyección internacional a través del hermanamiento con el Camino de Santiago, en Mirai. Estudios Japoneses 2(2018), 81-104.

\section{Peregrinaciones, viaje y turismo en Japón}

Los japoneses han viajado y han hecho turismo desde época muy temprana, aunque las características del viaje hayan ido evolucionando a la par que sus circunstancias políticas, económicas y sociales. La actividad del peregrinaje ${ }^{2}$ ha sido determinante en el desarrollo del turismo, ya desde los mismos orígenes de la civilización japonesa, hasta el punto de que resulta difícil distinguir en los viajeros sus motivaciones religiosas y las de puro disfrute, ${ }^{3}$ como son el paisaje o los lugares emblemáticos de su territorio, la gastronomía e, incluso, los placeres del sexo. Según Ishimori Shuzō, la popularización del turismo en Japón se remonta a comienzos del siglo XVII y sería, por ello, pionero en el mundo moderno. ${ }^{4}$

En su paradigmática obra antropológica sobre el turismo japonés, Nelson Graburn opina que, aparte de que los japoneses sean unos inveterados turistas desde tiempo inmemorial, probablemente sea Japón el país mejor organizado del mundo para esa actividad, y no solamente desde el punto de vista de infraestructura tecnológica actual. ${ }^{5}$

El origen, desarrollo y transformación de la actividad turística japonesa fue analizada, en primer lugar, por geógrafos ${ }^{6}$ debido a la relación estrecha entre turismo y territorio. Posteriormente, ese fenómeno fue analizado también por historiadores y antropólogos. ${ }^{7}$

Graburn señala una diferencia entre "lugar natural" y "lugar cultural" en los destinos de viaje, en el caso europeo. Sin embargo, afirma que esa distinción no resulta válida en el caso de Japón, ya que los lugares visitados por su entorno natural tienen también, con mucha frecuencia, un reconocimiento cultural e, incluso, sagrado. ${ }^{8}$ Por tanto, la actitud del turista japonés en la actualidad arranca de la que imperaba en la época medieval, cuando quienes emprendían una peregrinación lo hacían, básicamente, motivados por los siguientes factores: la visita a lugares de extraordinaria

2 Ishimori, Shuzō (1989): "Popularization and Commercialization of Tourism in Modern Japan". En Senri Ethnological Studies, 26. Osaka, pp. 179-94

3 Ashley, Ian (2015): "Space, Time and Heritage on a Japanese Sacred Site". En Stanley D. Brunn (ed.), The Changing World Religion Map. Sacred Places, Identities, Practices and Politics. New York: Springer, p, 528.

4 Ishimori, Shuzō (1989): “Tabi kara ryokô e". En Moriya Tsuyoshi (ed.): Nihonjin to asobi. Gendai Nihon bunka ni okeru dentô to henyô 6. Tokyo: Domesu Shuppan, pp. 92-112.

5 Graburn, Nelson (1983): To Pray, Pay and Play: The Cultural Structure of Japanese Domestic Tourism. Aix-en- Provence: Centre des Hautes Etudes Touristiques, p. 2.

6 Funck, Carolin (1999): Tourismus und Peripherie in Japan: Über das Potential Touristicher Entwlickung zum Ausgleich regionaler Disparitäten. Bonn: Verlag Dieter Born; Shöller, Peter (1980): Tradition und Moderne im innerjapanischen Tourismus, Erdkunde 34 (2): pp.134-50.

7 Ishimori, Shuzō (1989): "Tabi kara...”, op. cit, p. 101; Vaporis, Constantine (1995): "The Early Modern Origins of Japanese Tourism”. En Senri Ethnological Studies, n 38. Osaka, pp., 25-39; Guichard-Anguis, Sylvie (2009): "The culture of travel" ('Tabi no bunka') and Japanese Tourism”. En Guichard-Anguis \& Opkyo Moon: Japanese Tourism and Travel Culture. New York: Routledge, pp.1-17.

8 Graburn, Nelson (1983): To Pray..., op. cit., p.12. 
belleza (sitios sagrados, templos y santuarios), conocer y degustar la gastronomía local o disfrutar de los barrios de placer cercanos a las zonas de culto. ${ }^{9}$

En cuanto a tradiciones relacionadas con los viajes, en la era Edo era habitual realizarlos en grupo por parte de personas de similar franja de edad. Por otra parte, la tradición de despedir al viajero con obsequios o dinero, a los que este correspondía a su regreso trayendo obsequios adquiridos fuera, intensificaba la vinculación de quien partía con su lugar de residencia. Antiguamente, los miembros de cada comunidad viajaban en grupo subvencionados, en parte, por los vecinos (quienes se quedaban, esperaban poder viajar a la siguiente ocasión). Aquellos que permanecían, obsequiaban con dinero para gastos de viaje a quienes partían (餞別, senbetsu) y estos, a su vez, tenían la obligación moral, a su vuelta, de llevarles obsequios ( お 土産, omiyage). Esos objetos o productos representaban un medio de reinsertarse armoniosamente en su comunidad. ${ }^{10}$

Esta costumbre, perfectamente estructurada en la sociedad, deja entrever que quien emprendía un viaje, se convertía en un representante de todos los demás vecinos. En su camino, visitaba lugares que ellos hubieran deseado ver, disfrutaba de productos que los demás hubieran querido consumir y regresaba con regalos que cualquiera de ellos habría adquirido, de haberles sido posible realizar ese viaje. ${ }^{11}$

Por otra parte, el término que se refiere a “estar desocupado" (暇, hima), o el que define la diversión y el recreo (遊び, asobi) hacen evocar un disfrute egoísta. Por este motivo, quien se alejaba temporalmente de su lugar de origen se sentía liberado de culpa si dedicaba su tiempo a una actividad constructiva, de tipo espiritual y cultural, mientras se esforzaba por hacer partícipes a sus vecinos de la aventura que estaba disfrutando. ${ }^{12}$ El peregrino o el viajero en Europa experimentaban, por lo general, un extrañamiento y una separación de su entorno. En Japón, quien partía en visita a otros lugares reforzaba los vínculos con sus vecinos y reafirmaba su propia identidad personal así como el sentimiento de pertenencia a un ente local y nacional. ${ }^{13}$

En la actualidad, al igual que en el pasado, sigue produciéndose la tendencia a viajar juntas personas en la misma franja de edad, aunque no es tan común como antiguamente. No parece que haya desaparecido la antigua práctica del intercambio de regalos entre quienes parten y sus próximos. Carolin Funck explica que en caso de haber recibido senbetsu (dinero de despedida), quien parte está obligado a devolver omiyage, (souvenirs traídos del viaje), por una cuantía nunca inferior a la mitad del valor de lo recibido antes de partir, por lo que es preciso calcular bien antes de devolver un obsequio. ${ }^{14}$

\section{Proceso y cambio en el viaje turístico de Japón}

Voy a resumir a continuación, ciertos hitos importantes en el devenir del turismo nipón a partir de la posguerra y las campañas que han influido en la actitud de los japoneses hacia el viaje.

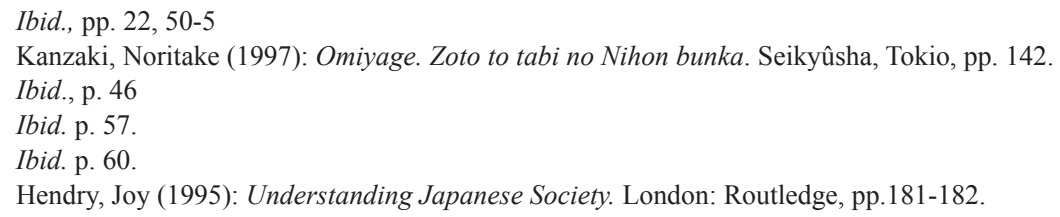




\begin{tabular}{|c|c|}
\hline $1963 \ldots \ldots \ldots \ldots \ldots$ & $\begin{array}{l}\text { Primeros signos de un turismo japonés de masas, orientado } \\
\text { hacia los viajes al extranjero y cuyo lugar fetiche era Hawái. }\end{array}$ \\
\hline $1964 \ldots \ldots \ldots \ldots \ldots \ldots$ & $\begin{array}{l}\text { En abril se crea la JNTO, agencia estatal del turismo. Puesta } \\
\text { en funcionamiento del tren-bala (Shinkansen). Juegos Olím- } \\
\text { picos de Tokio. }\end{array}$ \\
\hline $1968 \ldots \ldots \ldots \ldots \ldots$ & Nuevos trenes Limited Express. Se facilita el viaje individual. \\
\hline $1970 \ldots \ldots \ldots \ldots \ldots$ & $\begin{array}{l}\text { Expo de Osaka (más de } 60 \text { millones de visitantes). } \\
\text { Campaña publicitaria para la JNR (Japanese National Rail- } \\
\text { ways): } \\
\text { ディスカーバー. ジャパン “Discover Japan”. La JNR pone en } \\
\text { circulación el bono para viajar y cambiar de tren ilimitada- } \\
\text { mente en una zona determinada }\end{array}$ \\
\hline $1973 \ldots \ldots$ & $\begin{array}{l}\text { Crisis del petróleo y parón del turismo hacia el exterior. Surge } \\
\text { la tendencia AN-KIN-TAN: 安近短, que se decanta por } \\
\text { la preferencia por lo "barato, cercano y corto". Aumenta el } \\
\text { número de visitantes que viajan dentro de Japón. Se usa fre- } \\
\text { cuentemente el término Furusato, como reclamo para incitar } \\
\text { al viaje doméstico. }\end{array}$ \\
\hline $1978 \ldots .$. & $\begin{array}{l}\text { Campaña publicitaria: いい日旅立ち ('Ii hi tabidachi': un } \\
\text { buen día para partir), de la JNR. Nace un nuevo interés hacia } \\
\text { aspectos peculiares de su historia y de su cultura; (ascetas de } \\
\text { montaña o yamabushi y sus rituales chamánicos). }\end{array}$ \\
\hline $1983 \ldots \ldots \ldots \ldots \ldots$ & Inauguración de Tokyo Disneyland. \\
\hline $1984 \ldots$. & $\begin{array}{l}\text { Iniciativa Furusato zukuri: "Creación de un Japón de aldeas", } \\
\text { impulsada por el LDP, partido en el gobierno. }\end{array}$ \\
\hline $1984 \ldots \ldots .$. & $\begin{array}{l}\text { Campaña publicitaria creada para la JNR: “Exotic Japan”, エ } \\
\text { キゾチック. ジャパン, que mostraba imágenes de lugares em- } \\
\text { blemáticos del turismo religioso/ espiritual de Japón. }\end{array}$ \\
\hline $1987 \ldots$. & $\begin{array}{l}\text { La JNR se privatiza y se convierte en JR. Se pone en práctica } \\
\text { la Ley para el desarrollo integral de zonas vacacionales, con el } \\
\text { fin de impulsar el desarrollo del turismo local. }\end{array}$ \\
\hline $1991 \ldots \ldots \ldots \ldots \ldots \ldots$ & $\begin{array}{l}\text { Campaña publicitaria de la JR con el lema: “Tómate un des- } \\
\text { canso por Japón”, 日本を休もう (Nippon o yasumō). Tras la } \\
\text { aprobación de la Ley de desarrollo integral, un total de } 35 \text { pre- } \\
\text { fecturas contaban entonces con planes aprobados de infrae- } \\
\text { structuras vacacionales y de ocio. }\end{array}$ \\
\hline $2000 \ldots \ldots \ldots \ldots \ldots$ & $\begin{array}{l}\text { Se publica un artículo en la revista Aera, del periódico Asahi } \\
\text { Shinbun, } \\
\text { sobre el fenómeno power spot, titulado: 恋も仕事もパワスポ } \\
\text { 頼み } \\
\text { (Rogando por amor y trabajo en un power spot). }\end{array}$ \\
\hline $2003 \ldots \ldots \ldots \ldots \ldots$ & Campaña "Visit Japan", dirigida al turismo extranjero. \\
\hline
\end{tabular}




\begin{tabular}{|c|c|}
\hline $2005 \ldots \ldots \ldots \ldots \ldots$ & $\begin{array}{l}\text { Japón recibe la visita de cinco millones de turistas extranjeros. } \\
\text { Publicación del libro 神紀行 “Shin ki kō", de Ehara Hiroyu- } \\
\text { ki, en el que se señala a Ise, Kumano y Nara como Power } \\
\text { Spots o lugares de energía espiritual extraordinaria, que atraen } \\
\text { al turismo japonés. }\end{array}$ \\
\hline $2008 \ldots \ldots \ldots \ldots \ldots$ & Se crea la Agencia de Turismo de Japón (JTA). \\
\hline 2010 & Se declara en Japón el ‘Año de los Power Spots'. \\
\hline $2011 \ldots \ldots \ldots \ldots \ldots$ & $\begin{array}{l}\text { Tsunami en el Este de Japón y desastre de Fukushima. } \\
\text { Descenso del turismo extranjero. Movilidad interior de visi- } \\
\text { tantes japoneses. }\end{array}$ \\
\hline 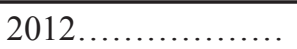 & Iniciativa "Fly to Japan Project", orientado al turismo exterior. \\
\hline $2013 \ldots \ldots \ldots \ldots \ldots$ & $\begin{array}{l}\text { "Meet the New Japan", campaña para atraer visitantes nacio- } \\
\text { nales y extranjeros. }\end{array}$ \\
\hline $2014 \ldots \ldots \ldots$ & $\begin{array}{l}\text { Aumento de un } 47 \% \text { en el turismo procedente del extranjero, } \\
\text { cuatro veces superior a las cifras del } 2003 \text {. A nivel local, au- } \\
\text { menta la preocupación por la masificación de lugares como } \\
\text { Kioto o Nara. }\end{array}$ \\
\hline $2017 \ldots \ldots \ldots \ldots \ldots$ & $\begin{array}{l}20 \text { millones de extranjeros visitan Japón. La previsión para } \\
\text { el } 2030 \text { se calcula en } 60 \text { millones de turistas procedentes de } \\
\text { fuera del país. }\end{array}$ \\
\hline
\end{tabular}

\section{Descubriendo Japón con nostalgia}

El año 1970 representa un punto de inflexión en la sociedad y en la economía de Japón. En ese periodo, ya pasados los Juegos Olímpicos de 1964, se afianzó el crecimiento económico iniciado con el evento y tuvo lugar la Exposición Internacional de Osaka. Por parte de las instituciones, se intentaba favorecer que los ciudadanos dispusieran de más tiempo para sí y de opciones para disfrutar de su ocio. Para ello, se creó en 1972 el "Gabinete industrial para el desarrollo del tiempo libre" (Yoka kaihatsu Sangyōshitsu余暇開発産業室), con el fin de coordinar la política legislativa y la puesta en marcha de planes de desarrollo para el ocio. ${ }^{15}$ Paralelamente, surgió por primera vez una preocupación seria por la contaminación atmosférica y la preservación del medio ambiente.

Con motivo de la mencionada Expo, la agencia estatal Japan National Railways (JNR) puso a disposición de los visitantes un número elevado de trenes que circulaban desde todos los lugares de Japón. En septiembre de ese año 1970, la Expo quedó clausurada y la famosa agencia de publicidad Dentsu recibió el encargo, por parte de la JNR, de lanzar una campaña que animase a los japoneses a viajar en ferrocarril por su país, con el objetivo de que no quedasen sin uso las nuevas líneas abiertas. Surgió así la campaña "Discover Japan” (Jisukabaa Japan, ジスカバージャパン), ${ }^{16}$ que se

15 Leheny, David Richard (2003): “The Rules of Play: National Identity and the Shaping of Japanese Leisure". Ithaca: Cornell University Press, p.79.

16 Curiosamente, esta campaña de "descubrimiento de los orígenes" tuvo su inspiración en otra creada en USA: "Discover America". 
materializó en octubre de ese mismo año y que invitaba a la población japonesa, especialmente a las mujeres jóvenes, ${ }^{17}$ a que conociesen paisajes, lugares, monumentos y costumbres de su propio país, a través del viaje.

Teniendo como primer objetivo la cuestión práctica de continuar con líneas de trenes en desuso, la iniciativa ofrecía al turista imágenes de lugares recónditos y poco identificables con el Japón moderno, animando a conocerlos por sí mismo y alcanzar, de paso, el descubrimiento de su propia cultura. La campaña la dirigió el ejecutivo de la agencia Dentsu, Fujioka Wakao. ${ }^{18}$ La palabra clave en la que basó su campaña fue tabi, 旅, que define un "viaje", pero que al contrario de la palabra ryokō, 旅行, sugiere, desde la época más antigua, un viaje -frecuentemente en solitario- de búsqueda espiritual o con el objetivo de cumplir una promesa. ${ }^{19}$ La otra palabra fue 発見: hakken, “descubrimiento”, “hallazgo”. Esto sugería un autodescubrimiento, que en japonés se expresaba con un término en inglés, algo japonizado: ジスカバー マイセルフ, Discover myself.

Entre líneas, el mensaje era: al partir, se tiene la oportunidad de descubrir algo desconocido y de encontrar un nuevo yo en el curso del viaje, quizás recuperando la propia identidad perdida. Por tanto, partir en busca del Japón original significaba, al mismo tiempo, ir en busca de la propia identidad (ya fuera perdida, ignorada o desconocida).

"Discover Japan", fue la primera campaña de masas dirigida al público en general. En ella se animaba a los japoneses a descubrir lo que aún quedaba del pasado premoderno en medio de su pérdida, mientras se transmitía un sentimiento de nostalgia por un tiempo que fue. Como la mayor parte de los japoneses residentes en ciudades más o menos grandes y con una gran influencia de la cultura occidental en su día a día, no habían tenido contacto ni con aspectos tradicionales ni con la vida rural de Japón, en esa situación, se creaba un sentimiento muy curioso ya que, posiblemente, el japonés medio no podía sentir nostalgia por algo que no había llegado a experimentar todavía.

El interés que impulsaba a muchos japoneses a visitar aldeas apartadas o bien lugares emblemáticos de peregrinación, lo define Graburn como "a nostalgic confirmation of their cultural landscape", ${ }^{20}$ una confirmación nostálgica de su propio paisaje cultural. "Discover Japan" se prolongó por ocho años, y continuó después con una secuela, hasta que fue sustituida por la campaña "Exotic Japan", ${ }^{21}$ en 1984.

\section{El exotismo de la propia tradición}

Para "Exotic Japan" se contó con el protagonismo de una figura muy popular entre los japoneses: Itsuki Hiroshi ${ }^{22}$, un intérprete de enka (tipo de canción equivalente a

17 La idea era que las mujeres jóvenes, cuando se casaran, pudieran transmitir a sus parejas aquello que hubieran asimilado en su viaje para “descubrir” Japón (Discover Japan). Ibid., p. 37.

18 El mismo Fujioka Wakao escribió un libro relatando los detalles de su campaña publicitaria: Fujioka, Wakao (1972): Kareinaru Shuppatsu. Jisukabaa Japan, Mainichi Shinbunsha, Tokyo.

19 La palabra tabi (旅) alcanza en el siglo pasado una gran popularidad en ámbitos muy diferentes. Véase: Guichard-Anguis, Silvie (2004): “A propos des 90 ans de la Revue Japonaise Tabi”. En : Le Globe: Revue Genevoise de Géographie, 144: Voyage, tourisme, paysage. pp. 85-102.

20 Graburn, Nelson (1983): To Pray..., op. cit., p. 63.

21 Gordon, Andrew (1988): “Tradition and Japanese Mass Media”. En Public Culture, pp.21-29.

22 Nacido en 1948, es muy popular también en Brasil, en donde ha actuado en varias ocasiones. 
la copla en España o al fado en Portugal). Tras una sucesión de imágenes que mostraban lugares muy significativos del budismo esotérico (como el Monte Koya), el cantante decía, como para sí:

\section{今日本は、どきどきするほど刺戟的だ (ima nippon wa dokidoki suruhodo shigekiteki da, "¡Japón es ahora algo tan estimulante, que hace palpitar...!"}

El énfasis de esta nueva campaña estaba en descubrir el exotismo dentro del propio país. Su mensaje era, que la visita a los lugares históricos de Japón podía resultar, incluso, más sorprendente que viajar fuera de sus fronteras. A través de las imágenes mostradas en la campaña publicitaria, se ponían de relieve aspectos que rememoraban el pasado, las costumbres y los modos tradicionales de la cultura japonesa, como si fueran contemplados con los ojos de un extranjero que visitara el país por primera vez. De nuevo, para el japonés medio la historia y la cultura de su país resultaban elementos casi desconocidos y, sobre todo, alejados de su experiencia cotidiana. Al mismo tiempo, la proyección de un Japón idealizado a través de su historia y su civilización milenaria así como la imagen de una vida rural serena y bucólica, como al margen del tiempo, parecen haber influido considerablemente en el desarrollo del turismo interno de Japón durante esos años. ${ }^{23}$

\section{Kumano, cuna del turismo espiritual en la tradición japonesa ${ }^{24}$}

El nombre de Kumano hace evocar los orígenes del estado de Yamato y el pasado mítico de Japón. En las primeras leyendas y crónicas japonesas, existen referencias acerca de sus lugares y de los hechos épicos y sobrenaturales que allí sucedieron. Pronto se convirtió en un destino muy frecuentado por los emperadores y la élite de la corte, la clase samurái y, finalmente, por viajeros curiosos y peregrinos de toda condición. Según la mitología japonesa, la diosa primordial Izanami tiene allí su tumba. ${ }^{25}$ A partir del siglo VII, los ascetas de montaña (yamabushi y shugenja) realizaban en esa zona sus prácticas ascéticas. Estas, incluían elementos del taoísmo y de la religión popular, del shintoísmo y del budismo esotérico. ${ }^{26}$

23 Oedewald, Marcus (2011): "Meanings of Tradition in Domestic Tourism". En Guichard-Anguis, Silvie \& Okpyo Moon (eds.). Japanese Tourism and Travel Culture. New York: Routledge. pp. 112-113.

24 A Kumano se refieren, en la antigüedad, tanto en el Kojiki (712) como en el Nihon Shoki (720). Ver también: Rodríguez del Alisal, Mariló (2012): "Kumano, narrativa oral de un paisaje sagrado". En. Pilar Garcés y Lourdes Terrón (eds.): Arquitectura y paisajes del imaginario japonés. Valladolid: Editorial de la Universidad de Valladolid, pp. ; Rodríguez del Alisal, Mariló: (2011): "Santiago de Compostela y Kumano: dos peregrinaciones hermanas ante un nuevo milenio". En Heikel Susana (ed.), Camino de Santiago: Encrucijada de lenguas y culturas; Actas del 65 Congreso de la Asociación Española de Profesores de Español (AEPE). Salamanca, pp. 403-414; Rodríguez del Alisal, Mariló (2004): "Peregrinaciones por caminos de agua: Kumano y Santiago de Compostela". En Almazán, David (ed.): Japón, arte, cultura y agua. Zaragoza: Universidad de Zaragoza, Prensas Universitarias de Zaragoza, pp. 213-226.

25 Aston, William George (trad.) (1886, 1956): Nihongi: Chronicles of Japan from the Earliest Times at A.D. 697. London: George Allen and Unwin, Ltd., pp, 21-22. El lugar se encuentra próximo a Kumano, en la prefectura de Mie.

26 Esos ascetas itinerantes realizaban sus retiros a lo largo y ancho de la cordillera de Kii (monte Ômine, monte de Yoshino, las montañas de Kumano), hasta el santuario y templo de Nachi donde practicaban ascetismo bajo su cascada. Fueron quienes sirvieron de guías a los emperadores y, más tarde, a todo tipo de peregrinos, ya que viajaban por todo el país difundiendo los caminos de Kumano y predicando para conseguir adeptos. 
Las referencias documentales sobre las visitas que la familia imperial y los nobles realizaban habitualmente a Kumano entre los siglos XI y XII son numerosas. Los emperadores retirados honraron Kumano con su presencia hasta 97 veces en el espacio de cien años. Acompañados de su séquito, que incluía más de mil personas, su periplo duraba aproximadamente un mes. ${ }^{27}$ Los ascetas yamabushi, expertos en la zona, guiaban al cortejo imperial y este se detenía en lugares ya prefijados para descansar, hacer abluciones, orar y recitar poesía. ${ }^{28}$ (Fig. 1)

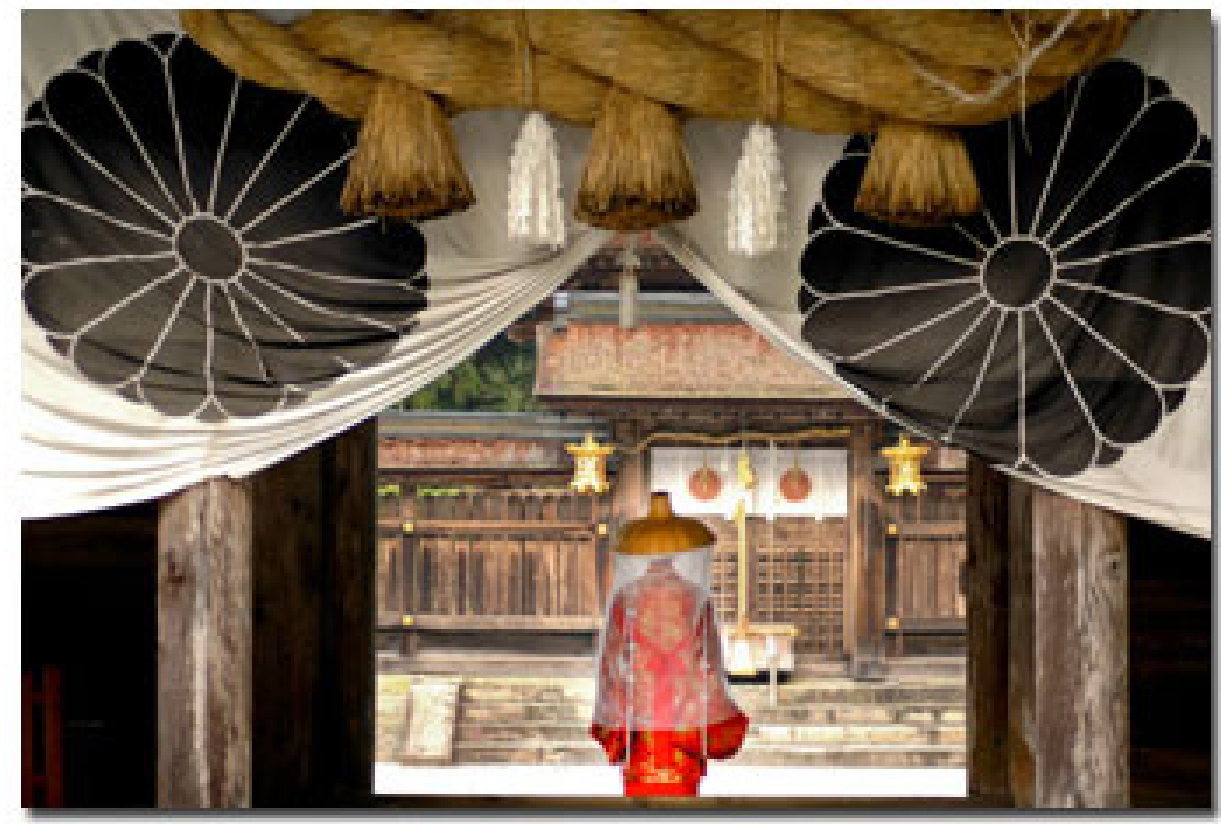

Figura 1: Santuario de Hongu en Kumano, con mujer ataviada como una peregrina noble en la Era Heian. www.tb-kumano.jp

A partir del siglo XIII, las monjas itinerantes llamadas etoki bikuni, realizaron una eficiente labor de difusión y de captación entre todas las clases sociales y en especial entre las mujeres, para lo que se desplazaban a lo largo y ancho del país. Como soporte visual, utilizaban rollos ilustrados en los que se mostraban mándalas representando escenas y paisajes de Kumano. ${ }^{29}$ Su labor influyó de manera importante en el flujo de peregrinos. ${ }^{30}$ Podría afirmarse que tanto los ascetas yamabushi como

27 Moerman, David (1997): "The Ideology of landscape and the Theater of the State: Insei Pilgrimages to Kumano (1090-1220)". En Japanese Journal of Religious Studies, $\mathrm{n}^{\circ}$ 24. Nagoya : Nanzan Institute for Religion and Culture. Nanzan University, pp. 347-374.

28 Miyake, Hitoshi (1999): "Rethinking Japanese Folk Religion: A study of Kumano Shugen”. En Kornicki, Peter Francis \& McMullen, James: Religion in Japan: Arrows to Heaven and Earth. Cambridge: University of Cambridge, Oriental Publications, III Series, pp.120-128.

29 Guichard-Anguis, Sylvie (2015): "Pelérinages, culture du voyage et tourisme au Japon: Le Zenkôji et Kumano". En Lecoquierre, B.-E Wauters: Pratiques du voyage dans un monde qui change. Le Havre, Rouen : PUHR, p, 272 .

30 Hosokawa, Kumiko (2007) : "Chikamatsu jōruri Shume Hōgan Morihisa ni egakareta Kumano Bikuni no etoki: e-iri jūnanagyōbon sashi-e no zuzō shiryō to shite no ikkōsatsu”.En Etoki kenkȳu, No . 20-21, pp. 199-213. 
las monjas bikuni fueron los primeros guías turísticos de Japón. En cierto modo, actuaban también como agentes de viaje, visitando en provincias a sus parroquianos y llevándoles amuletos y estampas de regalo, para que les sirvieran de protección en los años en los que los lugareños no podían hacer la peregrinación. (Fig. 2)

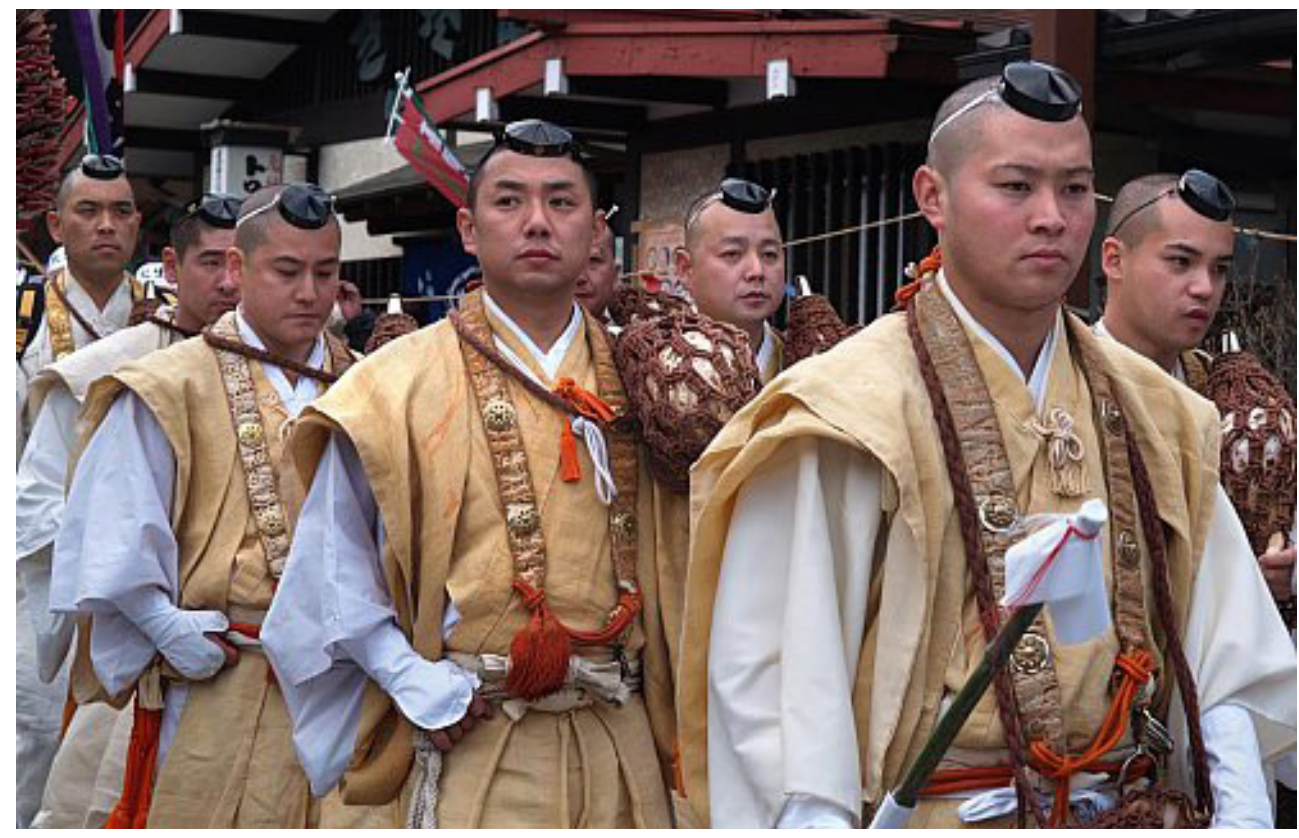

Figura 2: Ascetas Yamabushi con su atuendo característico. https://thewayoftheswordblog.wordpress.com/2016/05/04/yamabushi-y-sohei-los-monjes-guerreros-de-japon/

Tras el establecimiento del gobierno militar de Kamakura, situada en la zona oriental del país, la clase samurái ${ }^{31}$ eligió Kumano como lugar de peregrinación desplazándose por la ruta del Tōkaido, una vía que conectaba las provincias del este con las del oeste de Japón. A partir del siglo XIV, se convirtió también en un lugar de culto para las clases populares. En esta época, se había ido formando un grupo numeroso de guías yamabushi (a quienes se conocía como sendatsu, 先達) y el número de peregrinos era tan elevado que su estampa recorriendo los caminos se definió como "caravana de hormigas en dirección a Kumano".

En la era Edo, se decía que en el curso de la existencia había que peregrinar "siete veces a Ise y tres veces a Kumano". En aquella época, el gobierno de los Tokugawa imponía a los ciudadanos limitaciones muy severas para viajar fuera de la propia zona de residencia y solamente se conseguían con relativa facilidad los permisos necesarios por dos razones: por una peregrinación o por motivos de salud con el fin de visitar balnearios. ${ }^{32}$ Kumano, además de contar en su zona de culto con tres templos

31 Rodríguez del Alisal, Maria (2007): "New forms of Pilgrimage in Japanese Society”. En Rodríguez del Alisal, Maria / Ackermann, Peter / Martinez, Lola (eds.) : Pilgrimage and Spiritual Quests in Japan. London: Routledge, p. 75.

32 Vaporis, Constantin (1994): Breaking Barriers: Travel and the State in Early Modern Japan. Cambridge, MA. /Londres: Harward University, Council on East Asia Studies, pp.137-140. 
budistas y dos santuarios sintoístas, era un lugar famoso por sus aguas termales ya incluso desde la era Heian. Su visita tenía tanto fines religiosos como terapéuticos. (Fig. 3)

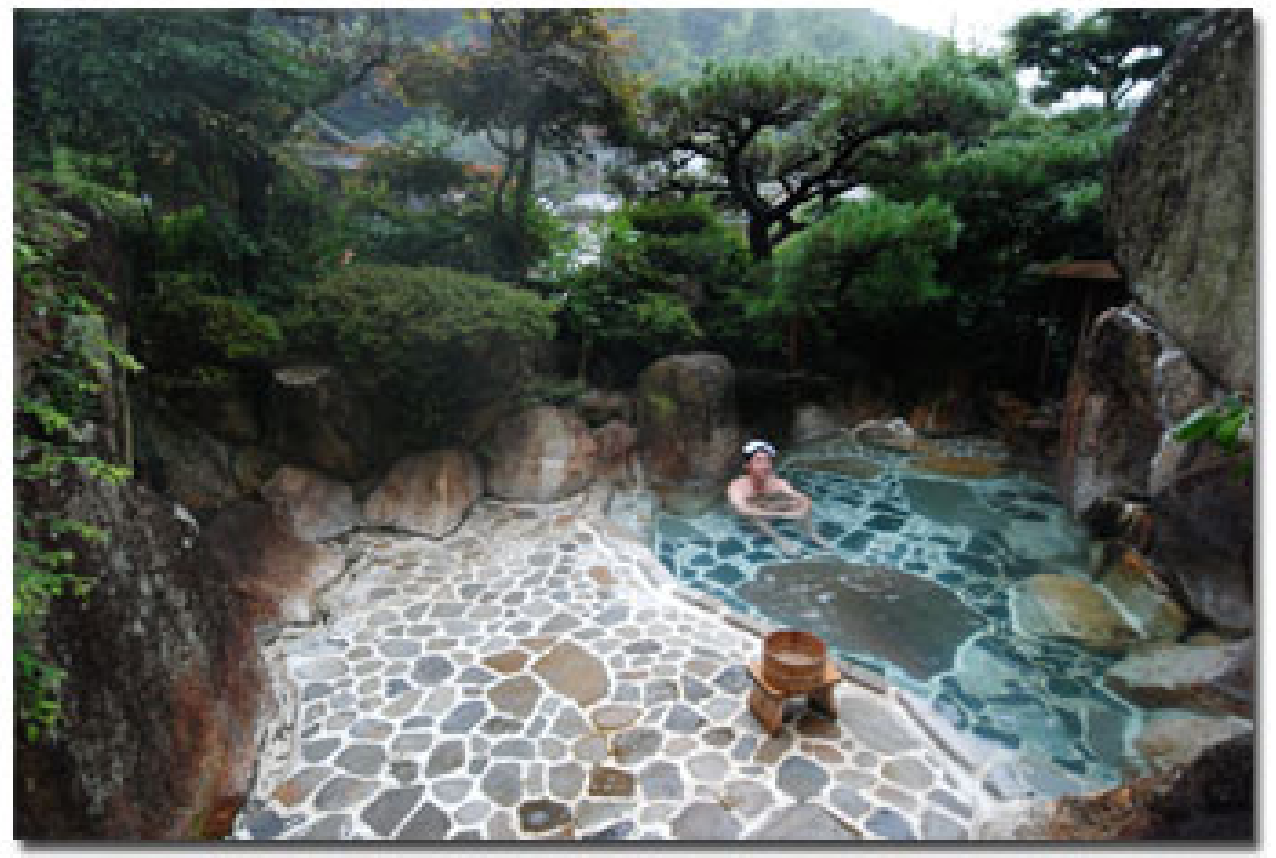

Figura 3: Balneario en Kumano. www.tb-kumano.jp

Otra característica importante de esta zona, es que se haya relacionado desde sus orígenes con la muerte, con el más allá, con la sanación y con el renacimiento a una nueva vida. Sus puntos de interés abarcaban su larga historia, sus aguas termales, los elementos religiosos y, por supuesto, su entorno natural. Este pertenece tanto a la categoría de "sitio sagrado", seichi (聖地) como a la de lugar de renombre por su entorno natural, meisho (名所). ${ }^{33}$ En Japón, ambas categorías están muy relacionadas, porque una zona reconocida por sus excepcionales características naturales se considera en sí "tierra sagrada".

La popularidad de los caminos de peregrinación en la cordillera de Kii experimentó un enorme declive desde finales del XIX hasta pasados los años cincuenta del pasado siglo. ${ }^{34} \mathrm{Su}$ verdadera recuperación se produce a partir de los años ochenta

33 Meisho (sitio célebre) fue un recurso literario hasta finales del Medioevo. Está relacionado con utamakura (frase poética) para referirse a un lugar concreto. A partir de la era Edo, el término meisho se popularizó y se convirtió en un punto con atractivo especial para ser visitado turísticamente por las masas. Véase: Ishimori, Shuzō (1997): "Tourism and Religion, from the perspective of Comparative Religion". En Umesao Tadao / Befu, Harumi \& Ishimori Shuzō (eds.). Japanese Civilization in the Modern World (IX) Tourism. Senri Ethnological Studies, 38. Osaka: National Museum of Ethnology, p.13.

34 Las leyes que prohibieron en la Era Meiji el sincretismo entre sintoísmo y budismo influyeron de manera determinante en su declive. Los ascetas yamabushi, que practicaban rituales taoístas, budistas y sintoístas fueron obligados a adherirse a una de las dos sectas del budismo esotérico: Tendai o Shingon. Poco a poco, abandonaron su labor de proselitismo y la actividad como guías de la zona. Además, al obtener el santuario de Ise el respaldo 
y se va afianzando en los noventa, hasta llegar a la actualidad. Sus lugares atraen por sus raíces históricas, por su relación tanto con el budismo y la otra vida como con el ideal vitalista del sintoísmo. Son muy admirados sus paisajes de montañas escarpadas, sus sendas boscosas y sus aguas termales, algo que es también digno de veneración en las creencias japonesas anteriores al budismo. (Fig. 4)

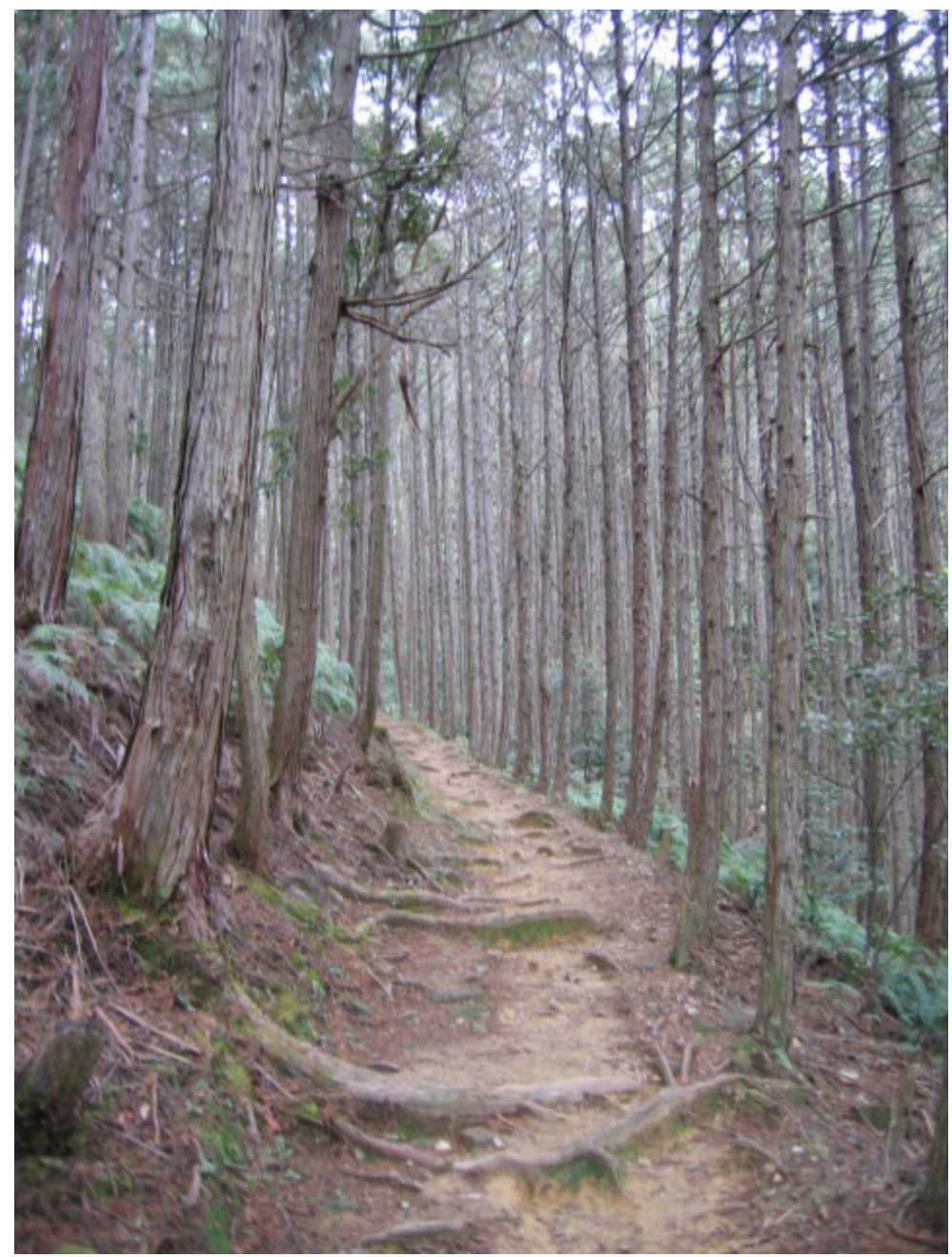

Figura 4: Senda boscosa junto al balneario Yunomine. Creative Commons

Después de un largo intervalo en el que esta peregrinación estuvo sumida en el olvido, el resurgir de la zona se produce por un nuevo interés hacia sus tradiciones, por un lado, y por la forma en la que se impulsa el desarrollo del turismo en Japón. ${ }^{35}$ (Fig. 5)

oficial de las autoridades, el flujo de peregrinos se canalizó hacia este destino y, como consecuencia, descendió mucho el número de visitantes hacia Kumano.

35 Ashiba, Yoho (1994): Shin kankôgaku gairon (Una nueva aproximación a los estudios turísticos) Kyoto: Mineruva Shobō, p. 25 


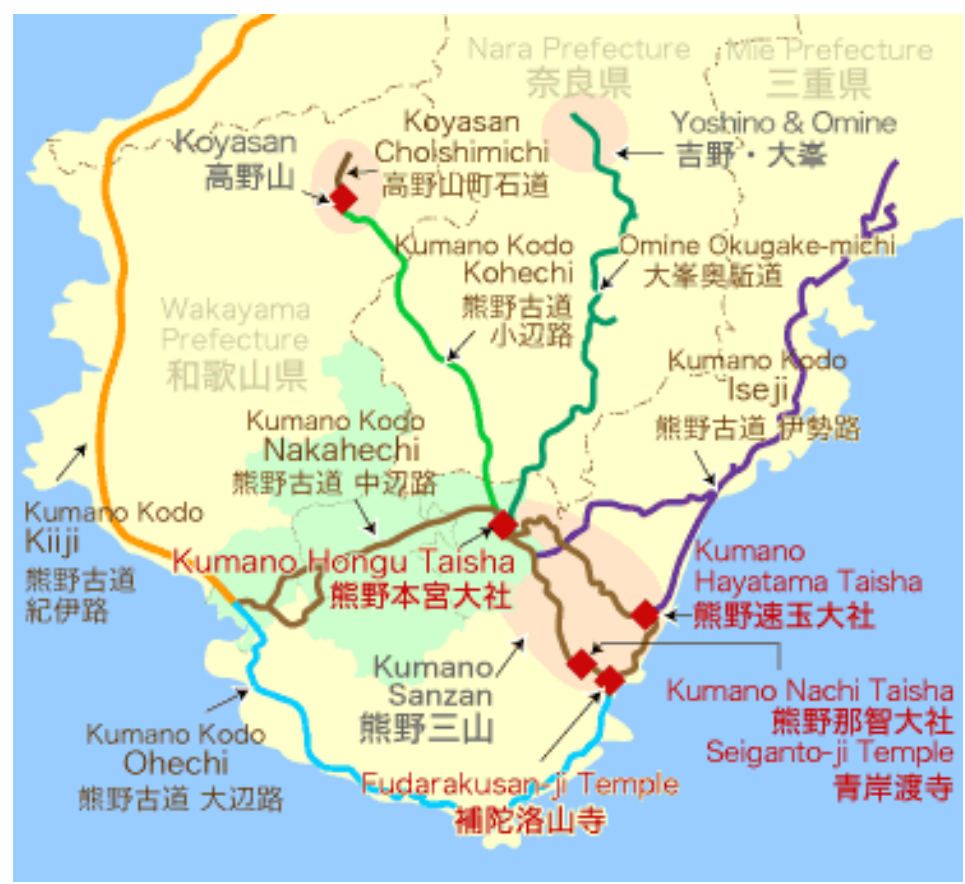

Figura 5: Mapa de los caminos a Kumano. http://www.tb-kumano.jp/es/kumano-kodo/

\section{Kumano, entre la tradición y el cambio}

El renacer de los lugares de la cordillera de Kii, donde se encuentran Kumano y sus caminos, no pueden desvincularse de los diferentes programas estatales y de las campañas publicitarias sobre viajes lanzadas a partir del 1970. ${ }^{36}$

Ya se ha comentado que dichas campañas recurren, frecuentemente, a la evocación de aspectos tradicionales y muy entrañables para los japoneses, como es el caso de la iniciativa Furusato Japan ${ }^{37}$ contenida en el proyecto Furusato Zukuri, ${ }^{38}$ "Crea-

36 Funck, Caroline \& Cooper, Malcolm (2013): “Japanese Tourism. Spaces, places and structures”. En $A$ sian Pacific Studies, Past and Present. Vol. 5. New York: Berghahn Books, p. 51.

37 La palabra furusato evoca el terruño de donde se proviene o el lugar donde tienen su origen los ancestros. En el imaginario popular evoca un lugar idílico y puro, tal como expresa la letra de la canción compuesta en el 1914 que lleva ese título y que hace palpitar por igual a todos los japoneses, aunque desde generaciones atrás, no hayan tenido contacto en absoluto con la vida en el campo: Morrison, Lindsay R. (2013): "Home of the Heart: the Modern Origins of Furusato". ICU Comparative Cultures, No 45, pp.1-27.

Más modernamente, surge otra canción del mismo título lanzada por el grupo Morning Musume, en 1999. Una película en el 1972 (Yamada Yoji), otra en el 1983 (Koyama Seijiro) y un film de animación del 2006, 1lamado, curiosamente, "Furusato Japan" (Nishizawa Akio). Existe, incluso, un asteroide descubierto por un japonés en el 2001, al que se ha llamado "Furusato".

38 Furusato Zukuri fue un proyecto del LDP (Partido Liberal Democrático), nacido en 1984, lanzado con la publicación de Nippon Rettô Furusatoron: ("Propuesta para hacer un Japón de aldeas"), presentada en la TV por el entonces ministro de Finanzas Takeshita Noboru quien, en 1987, publicó un libro titulado: Subarashii Kuni Nihon: Watakushi no furusato soseiron, por la editorial Kodansha en Tokyo. 
ción de un Japón de aldeas", iniciada a partir de 1970 e implantada en el 1984. En dicho proyecto, se hacía énfasis en dar a conocer las zonas donde el paisaje natural aún se conservaba casi intacto y las formas de vida permanecían exentas de los efectos de la industrialización. Atraer el turismo a lugares alejados de las grandes ciudades (de agricultura intensiva, ganadera y forestal) incrementaba el turismo nacional y servía para detener la creciente despoblación de esas zonas. Era un medio para reavivar la economía rural y favorecer el contacto de esas comunidades con el exterior.

El fenómeno Furusato de mediados de los años 80, presente tanto en el discurso de los políticos como en las campañas publicitarias de viajes y en el mundo del espectáculo, se convirtió en un verdadero símbolo nacional. ${ }^{39}$ Ese término, muy entrañable para los japoneses y cuyos sentimientos de nostalgia refleja a la perfección una canción compuesta en 1914 (Fig. 6), aspiraba tanto a recrear como a retener un mundo en vías de extinción, en una versión idealizada de la vida rural. ${ }^{40}$

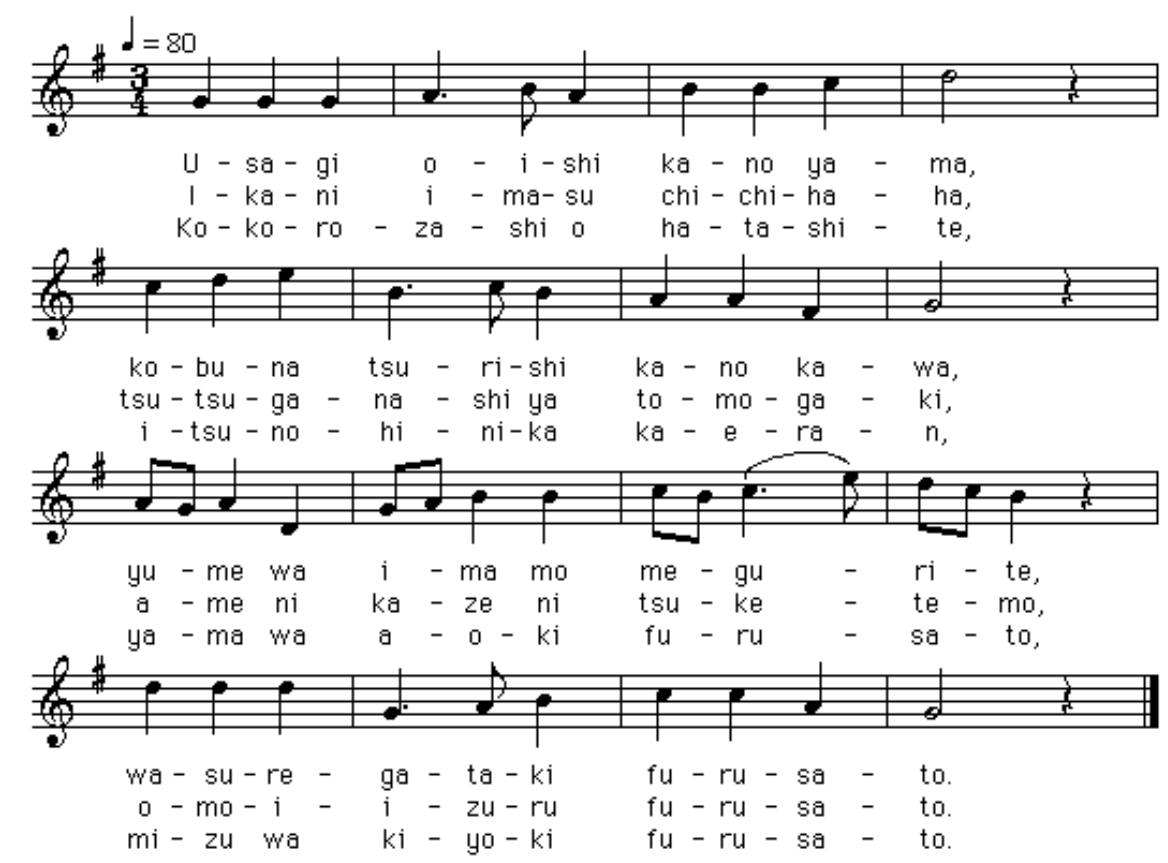

Figura 6: Letra de la canción Furusato de 1914. http://www3.u-toyama.ac.jp/niho/ song/furusato/furusato_e.html

Dentro de este proyecto, se diseñó el programa Furusato Mairi, ${ }^{41}$ "visita a la aldea". Esto incluía, por supuesto, incentivar los viajes a pueblos situados en zonas forestales o en montañas. Con el fin de mantener vivo el interés mutuo e incentivar unos vínculos duraderos, muchas comunidades comenzaron a ofrecer a los residen-

39 Robertson, Jennifer (1988): "Furusato Japan: The Culture and Politics of Nostalgia". En Politics, Culture, and Society, 1.4, pp. 494-518.

40 Kelly, William W. (1993): “Japanese No-Noh: The Crosstalk of Public Culture in a Rural Festivity”. En Public Culture 2.2, pp. 203-216.

41 Lindhart, Sepp \& Früstück, Sabine (eds.) (1998): The Culture of Japan as seen through its leisure. New York: State University of New York Press, p. 206 
tes de las ciudades (por medio de una cuota anual) una especie de membresía o un título de residente de honor. Por su parte, ese pueblo se comprometía a enviar a los miembros inscritos un boletín mensual de noticias informando acerca de sus actividades y sobre los festivales en la localidad. Incluían también información sobre la temporada de cosechas y las excursiones que se hubieran programado con el objetivo de contemplar la floración de los cerezos en primavera, el cambio de color en las hojas en otoño o cualquier otra actividad lúdico-festiva que se organizase. También se incluía el envío de productos agrarios locales, intentando estimular entre sus propios vecinos el orgullo por los cultivos orgánicos y la crianza de animales de granja dentro de estándares estrictamente ecológicos.

Como complemento a esta iniciativa, se diseñaron programas oficiales animando a los urbanitas a establecerse en zonas en proceso de despoblación. El estallido de la burbuja en la economía favoreció también esta tendencia de regreso al terruño o el traslado a lugares como Kumano y sus montañas. Precisamente en esta zona, la población de algunas aldeas había quedado reducida a la mitad entre 1955 y 1995, debido, entre otras causas, a la deforestación y a la forzada inactividad de los aserraderos. ${ }^{42}$

A principios de los ochenta y, por el impulso de las mencionadas campañas, se trasladaron a Kumano solteros y parejas jóvenes, que aprovecharon la tendencia al ecologismo para dedicarse a la producción de miel, a la agricultura orgánica y a la crianza de animales mediante estándares ecológicos. ${ }^{43}$ La presencia de esos nuevos habitantes produjo al principio cierto conflicto de relación con los residentes antiguos, ${ }^{44}$ aunque las diferencias fueran desapareciendo con el tiempo.

\section{Bosques sagrados, aguas milagrosas y alimentos naturales: el renacer en las forestas de Kumano}

Las campañas publicitarias y las iniciativas gubernamentales a las que nos hemos referido pusieron de relieve el pasado histórico y religioso de Kumano y de sus sendas de peregrinación entre los japoneses. Paralelamente, los proyectos de desarrollo "ecológico" atrajeron el asentamiento de gente joven.

Independientemente del interés suscitado por su pasado mítico, en el flujo de visitantes a Kumano influyó también cierto cambio en la actitud hacia el viaje experimentado por la sociedad japonesa: del "turismo de ver u observar" (miru kankō, 見 る観光) se pasó al “turismo activo" (suru kankō, する観光). ${ }^{45}$ Se mantuvo la simbología que siempre había rodeado a Kumano: por un lado, su connotación con la muerte y la otra vida, y, por el otro, la creencia en el poder de sanación que la visita a sus lugares aportaba a la salud y al espíritu. Los bosques de árboles centenarios y

42 Knight, John (2000): "From Timber to Tourism. Recommoditizing the Japanese Forest". En Development and Change. La Haya: International Institute for Social Studies, pp. 344

43 Knight, John (1997): “The Soil as Teacher". En Pamela Asquith \& Arne Kalland (eds.): Japanese Views of Nature: Cultural Perspectives". London: Routledge Curzon, pp. 247-255.

${ }_{44}$ Knight, John (2003): "Organic Farming Settlers in Kumano". En Waswo, Ann \& Nishida, Yoshiaki (eds.): Farming and Village Life in Twentieth Century Japan. London: Routledge Curzon, pp. 267-284, pp. 275-276.

45 Knight, John (1996): “Competing hospitalities in Japanese rural tourism”. En Annals of Tourism Research, 23. Amsterdam: University of Surrey, Elsevier, pp. 165-80. 
la abundancia de aguas termales, ríos y cascadas potenciaban esa asociación mental con la pureza, la recuperación física y el renacimiento espiritual. ${ }^{46}$

En 1982, la Agencia Forestal, dependiente del Nōrinshō (農林省, Ministerio de Agricultura, Bosques y Montes de Japón), acuñó un nuevo término shinrinyoku (森 林浴) o baño forestal..$^{47}$ Posteriormente se creó la Asociación Japonesa de Medicina Forestal que editó una serie de folletos informativos. En ellos se describían los efectos saludables de un paseo o la permanencia de un par de horas en el bosque, para reducir los niveles de estrés o el índice de colesterol y de azúcar en la sangre, siempre que se realizase correctamente. ${ }^{48}$

Cada año, entre 2,5 millones y 5 millones de japoneses participan en paseos "conscientes" por el bosque. Muchas empresas animan a sus empleados a realizar sesiones guiadas, con el fin de que su personal reduzca el estrés oxigenando su cuerpo y su mente. Los bosques de Kumano han sido objeto de un interés especial en las dos últimas décadas debido, en gran parte, a los movimientos que valoran la existencia y conservación de bosques sagrados y de sus templos y santuarios; lo que se denomina en japonés chinju no mori (鎮守の森). ${ }^{49} \mathrm{El}$ término significa, literalmente, “bosques de las deidades tutelares" y, en el pasado, se refería exclusivamente a la foresta que rodeaba los santuarios sintoístas y a los árboles que allí crecían espontáneamente. Hay que tener en cuenta que, en las primeras creencias de Japón, las zonas boscosas se consideraban tierra sagrada y sus árboles constituían soportes naturales donde descendía la divinidad. ${ }^{50}$

Desde hace ya más de veinte años, aquella tradición del bosque sagrado de los santuarios forma parte de una nueva aproximación al sintoísmo, que no es tanto religiosa como ecologista y orientada hacia la preservación de la naturaleza. Cierto es

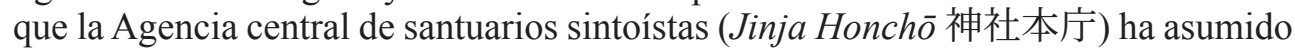
protagonismo en proyectos de preservación, ${ }^{51}$ aunque han surgido otras iniciativas promovidas por particulares, como las investigaciones llevadas a cabo por científicos como Miyawaki Akira ${ }^{52}$ y Ueda Atsushi. ${ }^{53}$ Con ellas, han conseguido llamar la atención sobre el valor ecológico de los tradicionales bosques sagrados y la im-

46 Morita, Emi (et al.) (2007): "Psychological effects of Forest Environment on healthy adults; Shinrinyoku (forest air bathing, walking) as a possible method of stress reduction”. En Public Health, No 1, Nagoya, pp., 54-63.

47 Existen al menos 52 centros reconocidos para la actividad shinrinyoku, dependientes de la Agencia Forestal de Japón, con la licencia de recetarlos y administrarlos en áreas determinadas. La actividad debe realizarse debidamente monitorizada por los especialistas de la Agencia. Estos enseñan a respirar correctamente, a sentir la tierra bajo los pies o las cortezas de los árboles bajo los dedos, a pasear o llevar a cabo determinados ejercicios físicos en el bosque y aprender a contemplar y escuchar a los pájaros o al viento, entre otras prácticas.

48 Qing, Li et al. (2009): "Effect of Phytoncide from Trees on Human Natural Killer Cell function". En International Journal of Immunopathology and Pharmacology. 22 (4), SAGE, London, pp. 951-9.

49 Este término fue utilizado por primera vez a finales del siglo XIX, por el novelista Tayama Katai (田山花袋: 1872-1930). En Rots, Aike (2015): “The Shinto Environmentalist Paradigm and the Rediscovery of Chinju no mori". En Japanese Journal of Religious Studies, 42/2:205-233. Nanzan Institute for Religion and Culture, pp. 218. Ver también: Ono, Ryohei (2010): "YŌgo chinju no mori no kindaiteki seikaku ni kansuru kŌsatsu". En Rand $\mathbf{O}$ sukêpu kenkyū, $\mathrm{N}^{\mathrm{o}} 73$, pp. 671-674.

50 Matsui, Keisuke (2014): Geography of Religion in Japan: Religious Space, Landscape and Behavior, Tokyo: Springer, p. 27

51 http://www.jinjahoncho.or.jp/en/publications/civilization/index.html (Consulta: 09/09/2017)

52 Miyawaki, Akira (2000): Chinju no mori (鎮守の森). Tokyo: ShinchŌ

53 Ueda, Masaaki (2001): “Shasō no hensen to kenkyū no shimyaku” (社葬の変遷と研究の史脈). En Ueda, Masaaki and Ueda Atsushi (eds.): Chinju no mori wa yomigaeru: Shasōgaku koto hajime (鎮守の森は更生る一社 叢学事始). Kyoto: Shibunkaku Suppan. pp.37-68. 
portancia de evitar su extinción. El tema se ha convertido en una preocupación a nivel nacional y, paralelamente, a partir de los años 90 del pasado siglo aparece con frecuencia ese concepto en títulos de libros, en folletos explicativos sobre la historia de los santuarios, la gestión forestal y la conservación del entorno paisajístico como un símbolo de la espiritualidad y de la identidad japonesa. ${ }^{54}$ En el caso de Kumano, desde que en el año 2004 sus sendas de peregrinación fueran declaradas Patrimonio de la Humanidad, el entorno natural que le rodea se encuentra doblemente protegido (Fig. 7). En cuanto a las aguas de Kumano, famosas desde la antigüedad, se ponen ahora de relieve en las guías de viaje, folletos y páginas web.

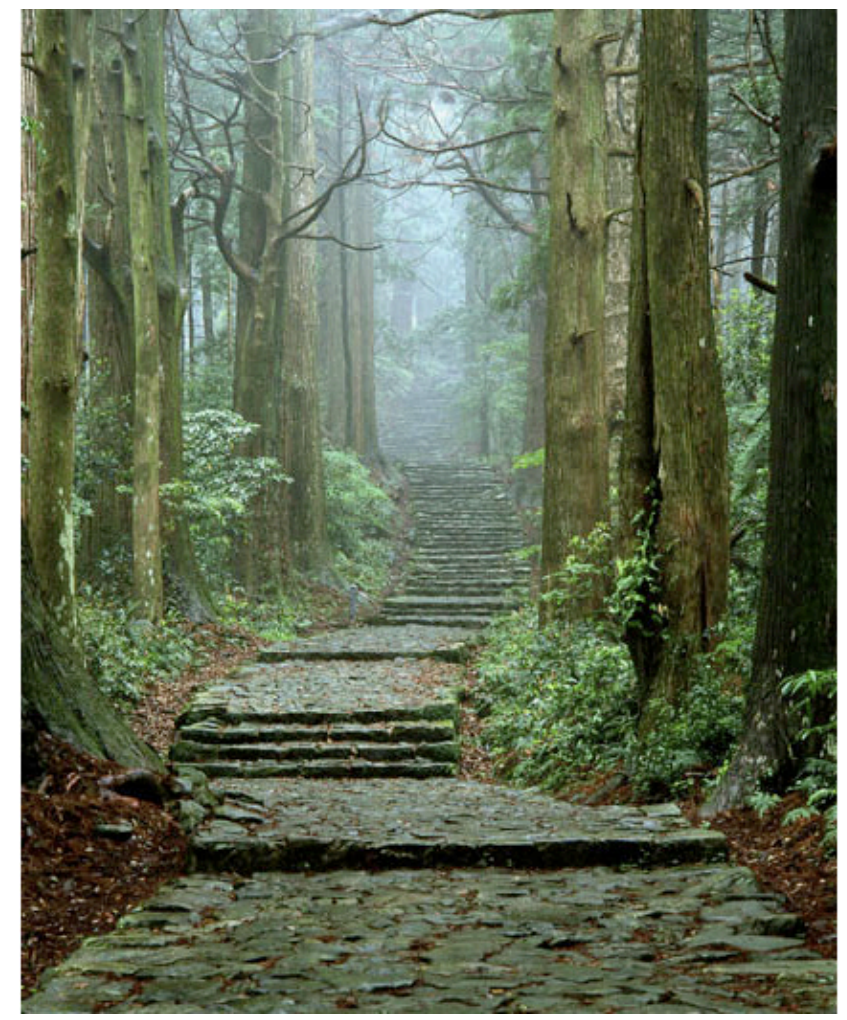

Figura 7: Bosque de Kumano. http://www.berenguela.com/el-camino-kumano-kodo/2010-04-03

\section{Ponerse a tono, física, mental y espiritualmente en Kumano}

Godai, los cinco elementos, representan el marco que contiene la esencia de Kumano, un lugar inmerso en la antigua tradición de culto a la naturaleza. Al sumergirse

54 Yamaori, Tetsuo (2001): Chinju no Mori wa naite iru: Nihonjin no kokoro o 'tsukiugokasu' mono (鎮守の森は 泣いている: 日本人の心を「突き動かす」もの). Tokyo: PHP Kenkyûsho. Ver también: Ueda Masaaki (2004): Chinju no Mori no genzô. En Ueda Masaaki (ed.): Tankyū “chinju no mori”: Shasōgaku e no shōtai (探求「鎮 守の森」一社叢学 への招待). Tokyo: Heibonsha. pp. 5-17. 
en la atmósfera de la tierra, el agua, el fuego, el aire y el cielo de los extraordinarios parajes naturales y espirituales de Kumano se estimularán sus sentidos y quizás experimente yomigaeri, ${ }^{55}$ pudiendo alcanzar el renacimiento en esta vida, el objetivo final después de haber llevado a cabo la azarosa peregrinación de Kumano. ${ }^{56}$

La cascada de Nachi tiene una larga tradición como lugar de actividades rituales y religiosas para los ascetas yamabushi. (Fig. 8). Estos practicaban y aún practican un entrenamiento espiritual colocándose bajo el salto de 133 metros. Para aquellos que no tienen esa fortaleza física y mental, se anuncia que la mera contemplación de sus aguas es una oportunidad única de sanación. ${ }^{57}$

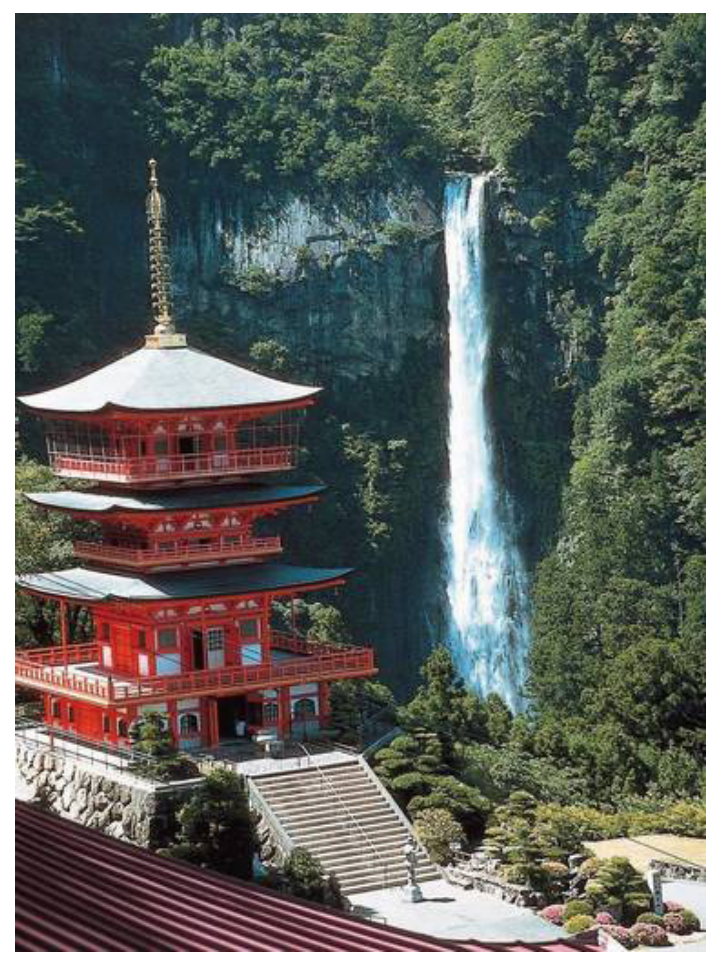

Figura 8: Pagoda y cascada de Nachi. https://www.japan-experience.es/ciudad-kumano/kumano-nachi-taisha

La cocina terapéutica, llamada yakuzen ryōri (薬膳料理), elaborada con ingredientes orgánicos, es otro de los reclamos importantes de Kumano: ${ }^{58}$ una gastronomía cuidadosamente pensada para ser fuente de salud (Fig. 9). Por otro lado, y si bien continúa habiendo agricultura o cría de animales mediante métodos convencionales,

55 Eckelmann, Alena (2015): "Reborn in Kumano". En Metrópoli (magazine), Tokyo http://metropolisjapan.com/ reborn-kumano/ [Consulta: 29/09/2017]

La palabra yomigaeri, traducida como renacimiento, significa literalmente: regreso de los infiernos o del más allá. Es decir, que implica una extinción previa y un renacimiento posterior.

${ }_{56}$ https://metropolisjapan.com/reborn-kumano/ [Consulta: Sept. 2017]

57 https://en.visitwakayama.jp/destinations/kumano/ [Consulta: 30/09/2017]

58 Chavez, Amy (Julio, 2017): "Hot spring-boiled eggs and Ancient Bento on the trail". The Japan Times. https://www.japantimes.co.jp/life/2017/07/22/food/kumano-kodo-hot-spring-boiled-eggs-ancient-bento-alongtrail/\#.WixRINThCIk 
la tendencia ecológica sigue en aumento. Los visitantes consumen esos productos en los establecimientos locales y adquieren aquellos que pueden ser transportados, siguiendo la costumbre de llevar al regreso de su viaje los recuerdos u omiyage para obsequiar a compañeros de trabajo, vecinos y familiares. Desde mediados de los años noventa, los productos más populares de Kumano son la miel, la mermelada, los frutos secos, pasta de miso mezclada con ayu (un tipo de pescado muy parecido a la trucha) y pasta de miso con cítricos. También el sen-bei (galletas elaboradas con arroz local, de cultivo orgánico). Todos ellos, se puede adquirir en los establecimientos locales, para llevar como obsequio a la vuelta del viaje.

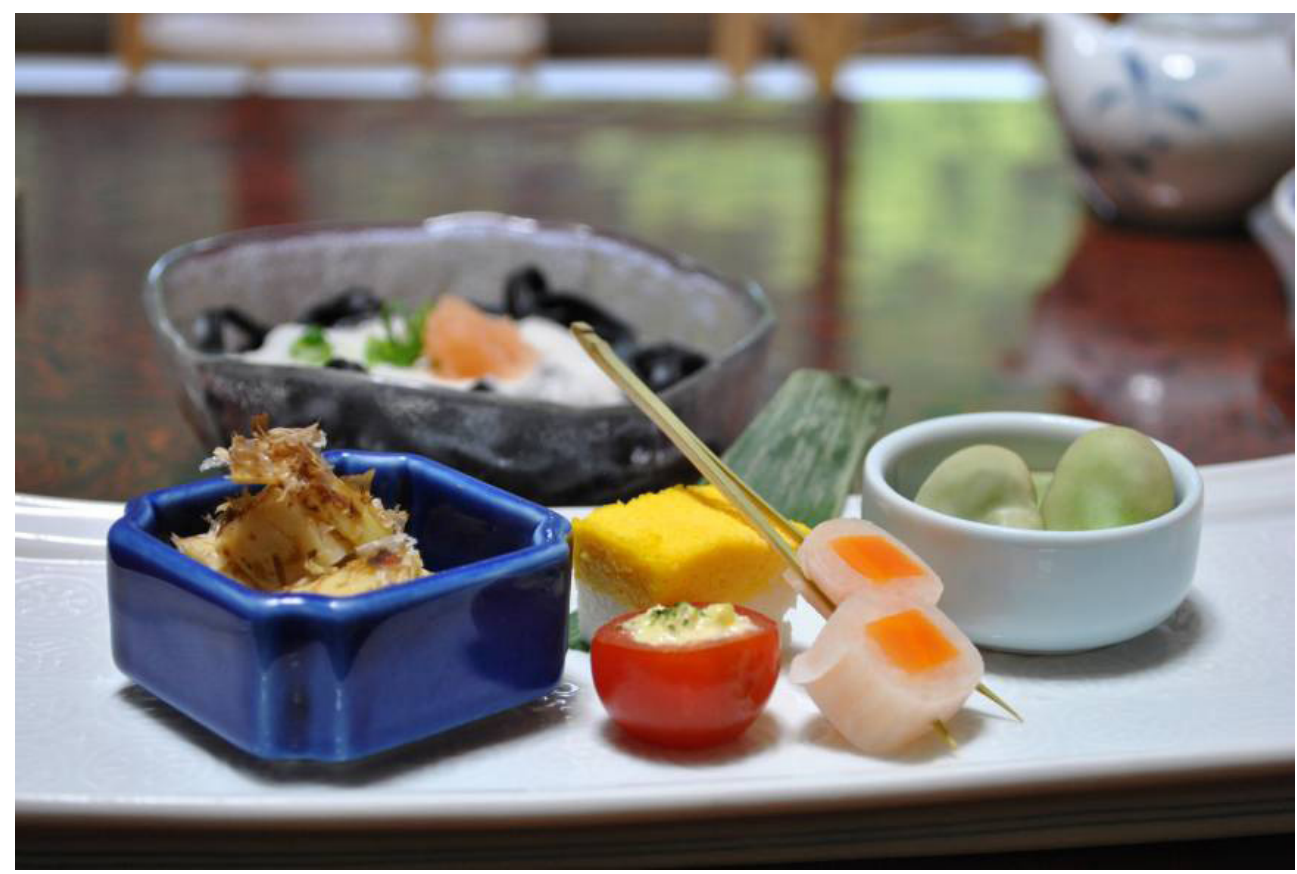

Figura 9: Gastronomía de Kumano: Yakuzen Ryori. https://www.japantimes.co.jp/ life/2017/07/22/food/kumano-kodo-hot-spring-boiled-eggs-ancient-bento-alongtrail/\#.Ww7QJ9SFPIU

\section{El fenómeno power-spot y Kumano ${ }^{59}$}

No es nada nueva la creencia de que existen lugares que irradian una energía especial capaz de influir en la salud física y en el equilibrio espiritual de las personas. Tanto en Japón como en otros lugares, los expertos señalan la existencia de los llamados vórtices, ${ }^{60}$ puntos de energía beneficiosa que se forman en la intersección de las

Estimo que este tema, al igual que el del hermanamiento internacional entre las sendas de Kumano y el Camino de Santiago, podría tener un tratamiento aparte en el futuro, por su importancia.

60 Los vórtices energéticos se encuentran en lugares específicos de energía telúrica. Cada uno influye de manera diferente en el ser humano y en el entorno: hay vórtices de energía vital, mental, espiritual y, entre estos últimos, 
líneas Hardrims y/o de las llamadas "líneas ley". En ellos se produce actividad tectónica y campos electromagnéticos. ${ }^{61}$

En el Japón de la era Heian, existía un departamento en la corte especializado en la geomancia ${ }^{62}$ y se recomendaba viajar en fechas determinadas a lugares concretos, por encontrarse en una dirección afortunada o por sus características especiales, que atraían diversos beneficios. Este tipo de motivación se redujo bastante a partir de principios del siglo pasado, debido a la influencia de la cultura occidental, aunque en las últimas décadas se observa un nuevo interés por los más diversos aspectos esotéricos.

En los años ochenta del pasado siglo, se utiliza con frecuencia en Japón el término power-spot (pauaa supotto), para referirse a los sitios de especial concentración de energía. En la década posterior, también a través de la influencia de las campañas publicitarias y de los artículos en revistas especializadas, había ido aumentando entre la población el interés por reencontrarse con los orígenes. Este hecho favoreció una nueva valoración de los mitos, de la historia, de la vida rural y de los lugares alejados de las ciudades. En décadas posteriores, se fue perfilando una tendencia a visitar sitios reconocidos por la fuerza energética que se les adjudicaba. Al mismo tiempo que el descubrimiento de esta nueva característica, la mayor parte de esos enclaves estaban ya muy vinculados con el pasado mítico e histórico de Japón.

El término power-spot se hace muy popular a partir del 2000, cuando se publican numerosos artículos en revistas dirigidas al público femenino. En el 2005 se publicó un artículo en el semanario Aera, perteneciente al periódico Asahi Shinbun, titulado: “Koi mo shigoto mo paua-supo tanomi (恋も仕事もパワスポ頼み. Rogando por amor y trabajo en los power spots)", en el que se demostraba que existía una verdadera fiebre por esos lugares (pauaa supotto buumu, パワースポットブーム), entre un sector amplio de la población japonesa. Esa popularidad fue en aumento, hasta que el 2010 fue declarado "Año de los power-spots", en Japón. Tanto era el interés suscitado, que los canales de TV se hicieron eco emitiendo programas que mostraban debates sobre esos aspectos. Un conocido asesor espiritual free lance, llamado Ehara Hiroyuki, aparte de publicar profusamente sobre el tema, se convirtió en comentarista habitual en los programas de TV, explicando detalles sobre la forma de obtener energía espiritual extraordinaria en los sitios denominados "de poder". Coincide ese momento con la depreciación del yen, que produjo una reducción de los viajes al extranjero de los japoneses, mientras que un mayor flujo de visitantes se dirigían, año, tras año, hacia destinos locales.

Kumano se ha beneficiado de este tipo de turismo espiritual. En el 2005, Ehara Hiroyuki publica: Shinki Kyō: Ise, Kumano y Nara (神紀行, 伊勢、熊野、奈良). En su nueva obra, Ehara se refería a esos "lugares de poder", donde puede recibirse goriyaku (ご利益), “el favor divino", que aporta beneficios de todo tipo a quienes los visiten. La página web oficial de la prefectura de Wakayama, hace constar los atractivos de Kumano, entre los que se encuentran los power-spots de su zona. ${ }^{63}$

los hay de alta emisión espiritual, situados sobre lo que se conoce como puntos estrella que tienen una vena de agua subterránea.

${ }^{61}$ En España, son muy conocidos, entre otros, Monserrat, los dólmenes de Antequera (que tienen vena de agua subterránea, especialmente el del Romeral), los Picos de Europa o el Camino de Santiago. Fuera de nuestro país, son famosos Stonehenge o el Machu Pichu.

${ }^{62}$ Kalland, Arne (1996): “Geomancy and Town Planning in a Japanese Community". En Ethnology Vol. $35, \mathrm{n}^{\circ} 1$. Pittsburg PA: University of Pittsburg, pp. 17-32

63 https://en.visitwakayama.jp/itineraries/kumano/ [Consulta: 05/11/2017] 
Repito que esta asunción no es ni nueva ni específica de Japón, ya que la creencia en los puntos de energía es antigua y se observa en otras partes del mundo, ${ }^{64}$ pero Ehara hace comprensible su teoría para sus paisanos, siendo algo muy arraigado en su propia cultura tradicional japonesa.

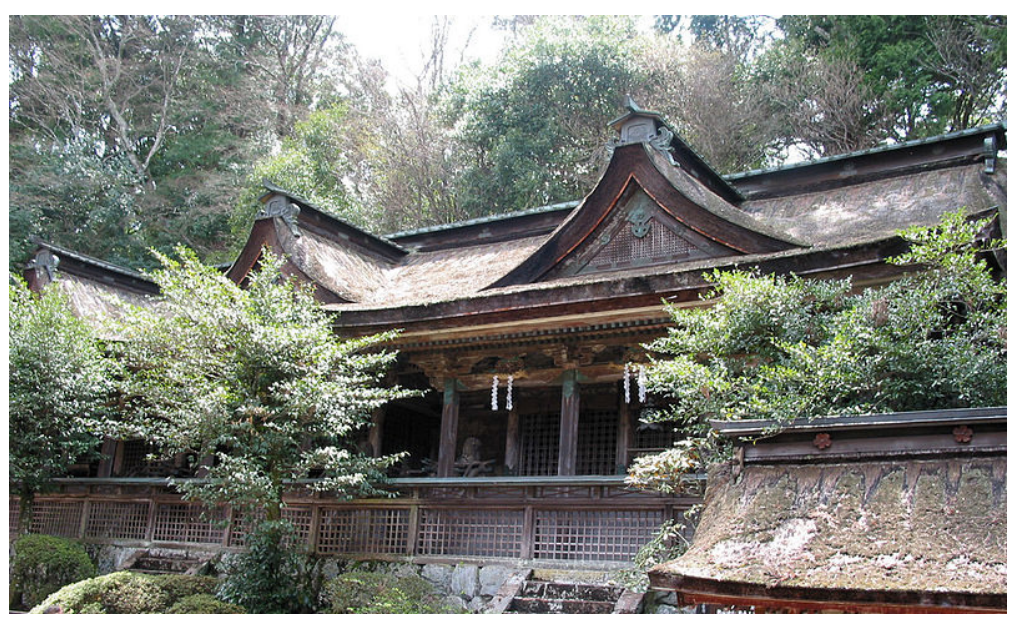

Figura 10: Santuario Yoshino Mikumari, Monte Yoshino, Prefectura de Nara. GFDL, Creative Commons Attribution ShareAlike 2.1 Japan License

\section{Vinculación internacional entre las sendas hacia Kumano y los caminos a Santiago}

Los primeros contactos entre el Camino de Santiago y las vías de peregrinación en la cordillera de Kii arrancan de mediados de los años 90. El acuerdo entre la Xunta de Galicia y la prefectura de Wakayama se cerró oficialmente en 1998, con la firma de un hermanamiento entre la Comunidad Autónoma de Galicia y la prefectura de Wakayama. De esta manera, comenzaron los intercambios entre los caminos de peregrinación de Santiago y los de Kumano, aunque hay que reconocer que se mostró más interés y participación por parte japonesa que por la española. A partir de entonces, las visitas de japoneses a Santiago aumentaron, varios monjes budistas

64 http://www.biohabitabilidad.es/puntos-energeticos-lugares-de-poder-vortex-points/ [Consulta: 05/11/2017]. Entre los lugares cargados de energía natural, existen unos que encierran depósitos minerales; otros deben su poder a los océanos, los mares, ríos, arroyos o volcanes; otros tienen la energía que procede de las construcciones levantadas por mano humana, como templos, santuarios, iglesias o fortalezas. En cuanto a las características de ciertos sitios "especiales", están los que se conocen como "puntos rejilla", que son lugares de alineación cósmica donde se cruzan las llamadas "líneas de ley"; lugares de energía especial, debido a la vegetación en su territorio: plantas sagradas, campos y bosques de árboles como los cipreses, las hayas o los robles. Por último, están los enclaves que guardan enterramientos o han sido testigos de hechos históricos de gran relieve. Podemos decir que Kumano contiene en su zona todas estas formas de energía.

Para información sobre lugares de energía singular y su consideración en el pasado, véase:

Watkins, Alfred (2005): Early British Trackways. Moats, Mounds, Camps and Sites. London: Cosimo Publishing. 


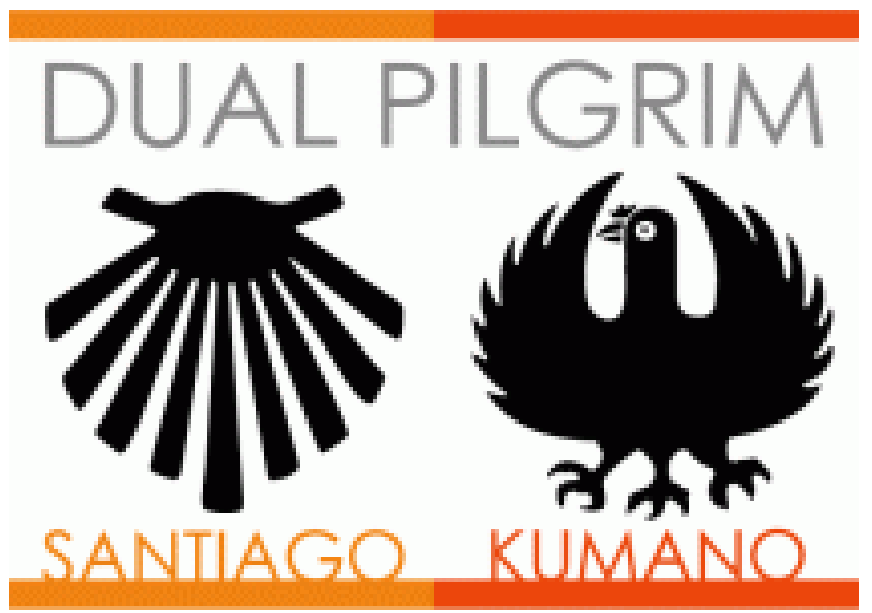

Figura 11: Insignia de Peregrino Dual. http://www.tb-kumano.jp/en/world-heritage/ dual-pilgrim/

realizaron a pie el camino francés y funcionarios de cada uno de los dos países se visitaron regularmente a través de diferentes programas, con el fin de conocerse y establecer futuros proyectos de colaboración comercial y de infraestructuras. Las ciudades de Santiago, en Galicia, y de Tanabe, en Wakayama, llevaron acuerdos de hermanamiento y cooperación, como consecuencia del hermanamiento entre sus sendas de peregrinación.

Los vínculos entre las diferentes sendas que recorren esa zona montañosa y el Camino de Santiago se afianzaron a partir del 2004, año en que la Unesco reconoció oficialmente como Patrimonio de la Humanidad a la extensa zona atravesada por caminos de peregrinación dentro de la cordillera de Kii, abarcando no solo a Kumano, sino al Monte Ōmine y al Monte Koya, a lo largo y ancho de tres prefecturas: Nara, Wakayama y Mie. (Fig. 10)

En el año 2007, miembros de la Oficina de Turismo de Santiago visitaron la ciudad de Tanabe, y en 2008 se firmó un protocolo de intenciones para establecer futuras colaboraciones entre los ayuntamientos de la mencionada ciudad y Santiago de Compostela.

En Junio del 2013 y, coincidiendo con el 400 aniversario de la visita a España del samurái Hasekura Tsunenaga, el príncipe heredero del Japón viajó a Santiago de Compostela e hizo parte del último tramo del Camino, refrendando con su presencia el hermanamiento entre ambos caminos de peregrinación. ${ }^{65}$ Ese mismo año las oficinas de turismo de cada uno de los dos países firmaron un "acuerdo entre ciudades", por el que se comprometían a llevar, con carácter permanente, una actividad de intercambio de experiencias y a poner en práctica un sólido programa de promociones conjuntas, culturales y comerciales, entre Tanabe y Santiago de Compostela. Como parte de dicho hermanamiento, se instituyó el estatus de "peregrino dual" (Fig. 11). Para refrendar dicho acuerdo, una delegación japonesa compuesta de autoridades de la prefectura de Wakayama, monjes del Monte Koya, vestales sintoístas y ascetas ya-

65 "Naruhito de Japón, un peregrino en el Camino de Santiago". En Revista Hola, 15/06/2013. https://www.hola. com/realeza/2013061565486/principe-naruhito-camino-santiago/ [Consulta: 28/10/ 2017]. 
mabushi (Fig. 12) visitaron Santiago de Compostela, quienes realizaron en el interior de la catedral una serie de rituales y danzas sacras ${ }^{66}$ A continuación, se celebró una ceremonia en el ayuntamiento de la capital gallega. ${ }^{67}$

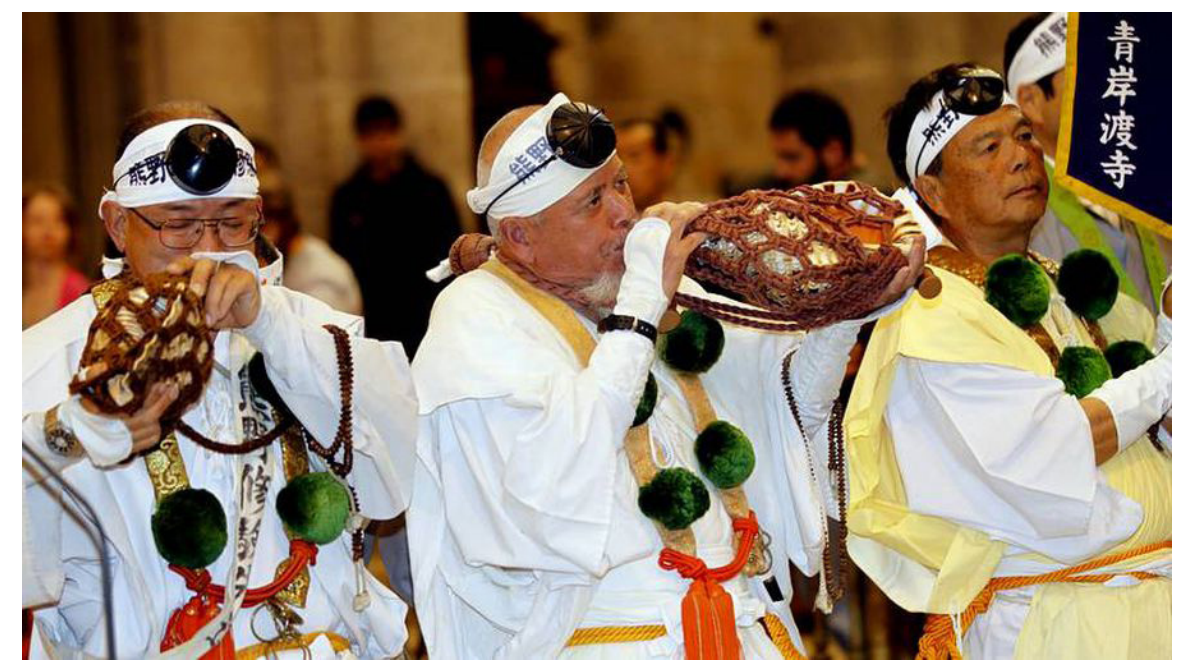

Figura 12: Yamabushi en Santiago de Compostela. 2014. https://www.lavozdegalicia. es/noticia/santiago/2014/05/13/monjes-budistas-sacerdotes-sintoistas-japoneses-celebran-catedral-union-tanabe-santiago/00031399993675948718398.htm\#

En su discurso, el alcalde de Tanabe manifestó que el Camino de Santiago iba a ser un modelo a imitar para Kumano, ${ }^{68}$ algo que se repitió después, por parte del gobernador de la prefectura de Kagawa, en relación al hermanamiento con los caminos de peregrinación Shikoku Henro, en Shikoku. ${ }^{69}$

Hay que tener en cuenta, que el hermanamiento está orientado, ante todo, a promocionar esos caminos, sus aspectos culturales y darles difusión; hacer mejoras en su señalización y en las instalaciones. Unos objetivos que no inciden particularmente en los aspectos religiosos.

A partir del 2015, quien desee realizar la peregrinación a Kumano y a Santiago puede solicitar una credencial unitaria, en la que se le estampan los sellos según vaya completando la marcha. Ese documento, que posibilita la obtención de dicha categoría de "peregrino dual", se consigue en varios puntos de la prefectura de Wakayama y de Galicia, como son las oficinas de Turismo de Tanabe o de la ciudad gallega.

${ }_{66}$ "Monjes budistas y sacerdotes celebran en la Catedral la unión de Tanabe y Santiago". En La voz de Galicia, $13 / 06 / 2014$.

https://www.lavozdegalicia.es/noticia/santiago/2014/05/13/monjes-budistas-sacerdotes-sintoistas-japoneses-celebran-catedral-union-tanabe-santiago/00031399993675948718398.htm [Consulta: 05/11/2017].

$67 \mathrm{http} / /$ www.santiagodecompostela.gal/hoxe/nova.php?id_nova=4145\&lg=ing [Consulta: 03/03/2015]

68 El gobernador de Kagawa, Keizo Hamada, con motivo del que sería el segundo hermanamiento de caminos de peregrinación (el Camino de Santiago y el de los 88 lugares santos de Shikoku o Shikoku Henro), se expresó de forma similar en el 2015, durante su visita a Santiago de Compostela.

69 Ian Reader ha sido hasta ahora el especialista que ha investigado el Shikoku Henro en mayor profundidad, y su obra más emblemática es Pilgrimages. Meaning and Practice in Shikoku publicada en 2005 por University of Hawai Press, Honolulu. 
El otro hermanamiento entre Japón y España al que me he referido, que recorre el circuito por los 88 lugares santos de Shikoku, fue firmado en agosto del 2015, al parecer con los mismos objetivos de desarrollo de infraestructuras, difusión de los caminos y márquetin que el acuerdo firmado entre Kumano y Santiago. ${ }^{70}$ Es aún pronto para establecer un balance. En cambio, el hermanamiento entre Kumano y Santiago llega a su vigésimo aniversario en el 2018, en esa fecha se cumplen 14 años desde el reconocimiento de la Unesco hacia los caminos en la cordillera de Kii y dicha efemérides marcará un hito para la mutua vinculación. Por tanto, en el 2018 habrá llegado el momento para poder extraer conclusiones respecto al camino recorrido en común y fijar objetivos comunes, con vistas a la relación de hermanamiento en los próximos veinte años.

\section{Conclusiones}

La peregrinación en Japón constituye una base muy importante de la espiritualidad japonesa y dicha actividad ha influido de manera notable en los orígenes del viaje, así como en el desarrollo turístico del país nipón.

Kumano tiene el privilegio de estar relacionado con los mitos de fundación de la nación japonesa y, además, disfruta de un entorno natural privilegiado, con aguas termales, bosques milenarios y altas montañas. Todo ello acrecienta su categoría sagrada. En la época actual, en el devenir de Kumano han influido las campañas publicitarias y las políticas turísticas institucionales. En este punto, los proyectos ideados a partir de los años setenta y ochenta del pasado siglo (desarrollo de zonas rurales, campañas oficiales y comerciales) hacen énfasis en la imagen de un Japón mítico y rural, que aún conserva la pureza de sus bosques y de sus aguas. Los lugares de Kumano se han convertido en leyenda, por su pasado mítico y por su relación con la muerte, por un lado, y con la sanación física y espiritual así como con el renacimiento a una nueva vida, por otro.

Redescubriendo esos lugares, tan exóticos a pesar de estar tan próximos para gran parte de la población, el viajero japonés tiene la oportunidad de establecer contacto con su pasado y de tomar conciencia de la propia pertenencia a una cultura milenaria. De esta forma, puede reafirmar su propia identidad, quizás ignorada u olvidada.

A través del viaje por el Kumano kodō, al japonés medio se le ofrece un doble camino: recuperar o reafirmar sus orígenes míticos y culturales y, al mismo tiempo, la oportunidad de sentirse miembro privilegiado de un mundo global, por medio del hermanamiento entre Kumano kodō y el Camino de Santiago. Precisamente es esta la peregrinación más emblemática de Occidente y que ha desempeñado un papel muy importante en el surgimiento y en el afianzamiento de una identidad cultural común europea.

En este aspecto, resulta de gran interés la iniciativa que han tenido las autoridades japonesas en su aproximación a la ciudad gallega y su Camino, independientemente de que su hermanamiento sea, básicamente, de tipo turístico, comercial y cultural. Resulta sencillo imaginar la dificultad que conlleva poner en práctica con éxito una colaboración estrecha con una peregrinación católica y, por tanto, de credo exclusi-

70 https://www.independent.co.uk/news/world/asia/japan-hopes-to-follow-camino-de-santiagos-path-to-marketing-success-with-750-mile-buddhist-a6794266.h [Consulta: 03/03/2015] 
vista como es el Camino de Santiago y que puede haber sido motivo de incomprensión por parte de algunos sectores conservadores del catolicismo. ${ }^{71}$

Resumiendo: el japonés que decida recorrer las sendas de la cordillera de Kii hacia Kumano, podrá apreciar el aroma mítico de su país, será consciente de sus raíces históricas y tendrá oportunidad de absorber la energía revivificadora de sus bosques, de sus aguas y de los alimentos cultivados ecológicamente en la zona. Paralelamente y a través del hermanamiento con el Camino de Santiago, se le abrirá el acceso al encuentro con una civilización ajena, de espiritualidad y cultura muy diferentes, pero de raíces también muy antiguas y, con un gran significado en la formación de Europa, así como en el desarrollo de su identidad y de aspectos culturales comunes entre sus países.

71 http://eponymousflower.blogspot.com.es/2014/05/cathedral-of-santiago-de-compostela.html [Consulta: 14/03/2018] 